East African Medical Journal Vol. 77 No. 11 November 2000

SCHIZOPHRENIA - THE SPIRIT POSSESSED 23 YEAR OLD MALE FROM RURAL KPANDO DZOANTI, VOLTA REGION IN GHANA: CASE REPORT

S.N.A. Turkson, MD, FWACP (Psych.), Department of Psychiatry, University of Ghana Medical School, P.O. Box 4236, Accra, Ghana.

\title{
SCHIZOPHRENIA - THE SPIRIT POSSESSED 23 YEAR OLD MALE FROM RURAL KPANDO DZOANTI, VOLTA REGION IN GHANA: CASE REPORT
}

\author{
S.N.A. TURKSON
}

\begin{abstract}
A case of a twenty-three year old rural Ghanaian male suffering from schizophrenia and presenting as "possessed by spirits" is reported. Treatment, and outcome by physical means with chlorpromazine; and implications for further research are discussed.
\end{abstract}

\section{INTRODUCTION}

In the World Health Organisation (WHO) sponsored International Pilot Study of Schizophrenia(1) it was shown that clinical diagnosis of schizophrenia in nine different countries including the US, UK, USSR, Denmark, Formosa, Nigeria, Czechoslovakia, Columbia and India were consistent and largely consistent with the project diagnosis.

The ICD-10(2) provides an operative definition of schizophrenia in countries that use the ICD- 10 criteria in clinical psychiatric practice. A case of schizophrenia presenting as "spirit possession" in a rural Ghanaian male is reported here.

The reason for presenting this case is that it focusses on how traditional beliefs and practices influence psychiatric disorders in different cultures, in this case, of the rural folks in Ghana, where the majority of the people reside. That symptomatology of psychiatric disorders has a great deal of religious flavour and maybe explained by the people's cosmology(3).

\section{CASE REPORT}

E.D., a twenty three year old single male from Kpando Dzoanti in the Volta Region of Ghana, a predominantly rural area of Ghana attended the author's general adult psychiatric outpatient clinic at the Accra Psychiatric Hospital (APH). He was accompanied by his mother and other relatives. The main complaint by the relations was that E.D. had been "spirit possessed" for the past three years. The onset of his "possession" was sudden and alleged to have started just before his final examination at Technical College. He stated that the spirit had taken hold of him and withdrawn his mind that he had become forgetful, and that he could not take his examinations. He was behaving "abnormally", roaming around the streets of the village but was unable to control it. "It was the spirits that was making me do it, and could even put thoughts into my mind, which are foreign to my religious beliefs as a Roman Catholic." He had been hearing voices from outside his head, commenting on his actions and criticising some of them, "these are from the spirit". His mother had noticed him making signs, talking and laughing to himself "as if responding to the spirit". He denied abuse of alcohol, cannabis and other drugs which was confirmed by his mother. He was initially admitted to another psychiatric hospital some two years previously for a similar illness, but left that hospital against medical advice. He denied any history of similar illness in the family and had no previous serious physical illness. On examination of his mental state, he appeared neat, well composed, well behaved and speech was normal except occasional derailment of his thoughts.

Auditory hallucinations were exhilated in the third person of "spirit" voices commenting on his actions, thought alienation, his mind being withdrawn by the spirit and other thoughts being inserted into his mind which are against his Catholic religion. He displayed passivity phenomena or delusions of control, the spirit making him laugh, talk and to roam about in the village.

Physical examination revealed a right-sided hydrocele, about the size of a tennis ball but he claimed he was not bothered by it. Otherwise the physical examination showed nil of note. The above phenomenology using Schneider's First Rank Symptoms(4), led the author to a diagnosis of acute schizophrenia in a 23 year old man. He was admitted and treatment was begun with chlorpromazine tablets: $200 \mathrm{mg}$ twice daily and eventually changed to injection fluphenazine decanoate monthly. His symptoms improved and he was discharged to outpatient care.

\section{DISCUSSION}

Possession disorders(2) have been described during the course of schizophrenic and other acute psychoses with hallucinations or delusions. Differential diagnosis had been considered to be multiple personality.

Indigenous practices in psychiatry in Ghana are flavoured by the traditional understanding of life and illness, which is largely centered on the belief in the unknown. Spirit possession is culturally accepted and may be precipitated by singing, clapping and drumming, strong emotions like fear, wonder or grief. In the case of E.D., such actions were not present but yet he believed he was possessed by a spirit which controlled his actions, and from whom he could hear.

In this country, where currently there is a proliferation of all kinds of pentecocharismatic churches and prayer houses as well as various shrines which profess to heal the mentally ill, there is no doubt in the author's mind that many patients such as E.D. could be found in such places. Indeed it is a widely held belief among some Ghanaians that there is high prevalence of mental illness among 
Ghanaians who attend traditional shrines and prayer houses and camps. These people perhaps see every illness in terms of spiritual causes just as E.D. and that illness is a direct result of spirit possession.

It is suggested that a wider community research in these prayer camps, healing centres and shrines might shed some light on the exact prevalence of mental illness among the group and the type of mental illness encountered. Like E.D. some might benefit from psychopharmacological methods of treatment.

It is suggested that an extensive and in depth research in these prayer camps, healing centres and shrines should be carried out to discover these patients, who will benefit from psychopharmacology.

\section{ACKNOWLEDGEMENTS}

The author wishes to acknowledge with thanks, the secretarial assistance given to him by Mr. Samuel Tagoe of the Department of Psychiatry, U.G.M.S.

\section{REFERENCES}

1. IPSS: The International pilot study of schizophrenia - Vol. 2, WHO, 1973.

2. ICD-10: WHO (1992): International Classification of Diseases: Chapter V: Mental and Behavioural Disorders. WHO, Geneva

3. Osei, A. FWACP Dissertation: Indigenous Practices in Mental Health in Ghana (unpublished), 1999.

4. Schneider Kurt. Clinical Psychopathology (translated by M. Hamilton and Stratton), New York, 1959. 